\title{
A Review of the Navigation HCI Research During the 2000's
}

\author{
$\underline{\text { doi:10.3991/ijim.v4i3.1270 }}$ \\ Teija Vainio \\ Tampere University of Technology, Tampere, Finland
}

\begin{abstract}
Two of the common problems associated with navigation research in the field of human computer interaction (HCI) systems and human factors, are the relatively narrow view that the display is able to provide for a large information space, and the impact that a diversity of contexts has on the users' divided attention. In recent years, much research has been focused on the development of navigation presentation techniques to address the first problem, and the development of capturing the context with multimodal interaction in order to address the second challenge. However, the growing number of new terminologies and techniques that has been developed has caused considerable confusion for HCI researchers, consequently making the comparison of these techniques and the generalisation of empirical results of experiments very difficult, if not impossible. This article provides a taxonomy of current navigation research, which describes clearly the navigation research on desktop and non-desktop environments; it also helps to identify research domains that afford and promote the direction of navigation research. This review reveals gaps where navigation research has identified challenges but has not yet explored them.
\end{abstract}

Index Terms-Human Factors, Navigation, review

\section{INTRODUCTION}

Over 500 years ago some of the most well-known feats of navigation were accomplished when Christopher Columbus sailed across the Atlantic Ocean. Even then, he knew that navigation tasks could be practiced beforehand in order to find an easier route. During Columbus's era, navigation was understood as moving from one place to another and finding one's way in a real physical environment. Hundreds of years later, navigation now also signifies something else for those of us who live with hypermedia applications, search information within large databases, listen to driving instructions on a SatNav device in our cars, and locate local sights as pedestrians using mobile tourist guides.

Navigation has also been the focus of a huge amount of scientific research over the past decades. For example, in 1948, Tolman (1948) argued that navigating is to some extent a personal ability or skill, and a human being creates a personal cognitive map in order to be able to navigate better in the world. Lynch (1960) explored to what extent these cognitive maps could support navigation in Chicago during the 1960s. In this type of navigation research, the focus is on wayfinding, i.e., searching and finding a route from point A to point B. Thus, studies on wayfinding not only cover the wayfinding task in real environments, they are also the focus of navigation research in three-dimensional virtual environments; (see for example
Vinson, 1999, Cliburn et al., 2007). In virtual environments, users are exploring great quantities of information and one of the navigation challenges lies in how to support users in order to enable them to find what they are searching for. Three-dimensional virtual environments are also an example of a certain kind of large information space with interconnected and massive amounts of digital files or documents. Research on how to navigate in large information systems seems to focus on how to support document navigation for example, how to move with perspective-drag technique (Guiard et al., 2007)or scroll and zoom between documents; see Mehra et al. (2006). As stated, navigation research has an extensive and broad field of interesting starting points. However, in order to understand navigation research and to be able to take steps forward in the future, researchers should be able to place their own scientific contributions within the wider context of research into human computer interaction. This review of navigation research in the 2000s draws upon the bigger picture of scientific navigation research. The primary objective of this study is to capture an overview of navigation research being conducted in the human computer interaction research field for the period of 2000 to 2007.

Why cover this wider field of navigation research and not just focus on, for example, navigation research on mobile devices? The argument for taking the wider view is two-fold. First, it is assumed that navigation research shares some general characteristics whether it concerns mobile or desktop environments. One example of this similarity uses the concept of a landmark. A 'landmark' is defined by Lynch (1960) as an external point-reference, which a user (an observer) does not enter. Landmarks are physical objects, and they may be local or distant, or even mobile; they may include a storefront, a tower, or the sun. The impact of using landmarks to support navigation has been explored, for example, when studying auditory landmarks in mobile navigation (Baus et al., 2007), designing guidelines for landmarks to support navigation in virtual environments (Tory et al., 2004), developing dynamic landmark placement as a navigation aid in virtual worlds (Cliburn et al., 2007), and analyzing the navigability of Web applications for improving blind usability (Takagi, Saito, Fukuda and Asakawa, 2007). Therefore, it can be assumed that there might be other interesting similarities concerning navigation research across various environments and conducted with different devices. Second, the differences that, for example, desktop and non-desktop navigation research may possess could reveal something critical. For example, until recently multimodal interaction was the focus of navigation research mainly in desktop navigation; see e.g Wall and Brewster (2006) . Thus, Jöst et al (2005) explore the influence of social and situational 
contexts on multimodal interaction; they stated that multimodality can enhance the usability of navigation tasks for mobile pedestrians as well. Finally, even if navigation research in human computer interaction has been conducted in desktop environments for longer than in nondesktop environments, it is still interesting to examine how some of the key concepts used, that is, navigation, landmarks, and wayfinding, have counterparts in navigation in a real physical environment. When reviewing navigation research both within the desktop and non-desktop research, it assumed that the possible shift that occurs between these two areas can be acknowledged.

This paper is organized into five main sections. Following the Introduction, the Methodology section introduces the steps of the reviewing process. The third section focuses on the characteristics of the navigation research from the 2000s studied in this paper, categorized according to the technology and keywords focus of the research and key concepts. Section four describes the key results and possible gaps that should be taken into account in future research agendas in the field of navigation research. The fifth section discusses the implications of this description for the research of navigation in the field of human computer interaction.

\section{MethodOLOGY}

The main aim of this review is to describe the path for future research of navigation for any researcher in the field of human computer interaction. The research questions in this study are as follows:

1. What is the focus of navigation research in the field of human computer interaction?

2. What types of results has navigation research in the 2000s accomplished?

3. What are the main challenges and directions to fill in for future research?

The published navigation research articles were examined in the following stages:

To identifying the relevant articles, the first three steps were taken (see Swanson and Ramiller, 1993) 1): selecting/searching articles for review 2) filtering relevant articles and 3) identifying content and structure. In addition, in order to analyze the content, the following four steps were taken: 4) evaluating the content and structure 5) grouping according to the objectives 6) clustering and validating and finally 7) triangulating (see Patton, 2002).

The research method conducted for this study was content analysis. In previous studies reviewing HCI research and research methods, see e.g. (Kjeldskov and Graham, 2003); there are only a few, if any, reviews of navigation research. In this study, the articles published from 2000 to the end of 2007 were included from five HCI-related conferences and three journals. The selected articles were blind-reviewed and were published in:

1. SIGCHI conference on human factors in computing systems (CHI)

2. Nordic conference on human computer interaction (NordiCHI)

3. Human computer interaction with mobile devices and services (MobileHCI)

4. International conference Intelligent User Interfaces (IUI)
TABLE I.

CONFERENCE PROCEEDINGS AND JOURNALS STUDIED

\begin{tabular}{|l|c|c|c|c|}
\hline \multicolumn{1}{|c|}{ Conference or journal } & Title & Abstract & Keywords & Total \\
\hline CHI 2000-2007 & 11 & 51 & 30 & 58 \\
\hline NordiCHI 2002-2007 & 1 & 5 & 4 & 6 \\
\hline MobileHCI 2004-2006 & 5 & 21 & 13 & 23 \\
\hline IUI 2000-2007 & 7 & 20 & 20 & 29 \\
\hline $\begin{array}{l}\text { HUMAN-COMPUTER } \\
\text { INTERACTION 2000-2007 }\end{array}$ & 5 & 4 & 1 & 5 \\
\hline TOCHI 2000-2007 & 2 & 13 & 7 & 14 \\
\hline PUC 2000-2007 & 4 & 11 & 4 & 14 \\
\hline Total & 35 & 125 & 79 & 149 \\
\hline
\end{tabular}

\section{Human Computer Interaction}

6. ACM Transactions on Computer Human Interaction (TOCHI)

\section{Personal and Ubiquitous Computing (PUC)}

All the articles have been peer-reviewed and the journals and conferences selected have an established reputation as the main publications for HCI research. Out of more than 200 articles consulted, 149 were kept for more detailed analysis.

The articles were selected using the following criteria:

1. navigation is mentioned in the title, or

2. in the abstract, or

3. as one of the keywords.

The total number of articles found is summarized in Table 1. Where overlap was found between the articles, that is, where navigation is mentioned in the title and in the abstract/keywords, or navigation is mentioned in the abstract and in the keywords, those articles were removed. The total number of selected articles was 149.

\section{Characteristics OF NAVIGATION RESEARCH}

Navigation is the process of moving through an environment, either virtual or real. Thus, there are different kinds of navigation; it can, for example, be goal-directive or explorative (Darken and Sibert, 1996). Wayfinding is an essential part of navigation. The tasks of wayfinding can be categorized as naïve search, primed search, and exploration. Purposeful movement during navigation improves with increased spatial knowledge of the environment. Spatial knowledge can be described as three-level information: landmark knowledge, procedural knowledge and survey knowledge. (Darken and Sibert, 1996). Based on the articles reviewed for this study, navigation research can be roughly categorized into research on navigation within information systems, such as in databases, web pages, other digital documents and three-dimensional virtual environments; and on navigation with information systems, such as mobile guidance systems or wearable maps. Furthermore, navigation research can focus on 1) navigation with information systems designed for desktop computers or 2) navigation with information systems designed for non-desktop computers or 3) navigation in real physical environments with non-desktop computers. The two latter types of research include mobile computers, large displays, wearable computers and embedded technology. The objects, that is, navigators, are usually human beings but in recent research, studies on robots navigating 
in real physical environments (Amant and Christian, 2003) have been explored as well.

Navigation research can be divided into several categories according to the technology that is used when users are completing the navigation task. Based on the articles reviewed, navigation research during the 2000s can classified in the following ways:

1. Navigation in information systems with desktop computers

2. Navigation in 3D virtual environments with desktop computers and other type devices (e.g. haptic)

3. Navigation in information systems with mobile devices

4. Navigation in information systems with wearable devices

5. Navigation in information systems with embedded technology

Even with technology-based classification, which seems to be clear and well-restricted, there are some cases that are not easy to categorize according to the technology. For example, research on multi-device environments and social interaction are not so well suited to this type of technology-driven classification.

The primary motivations for navigation can be exploring or searching for information or completing a wayfinding task in all of these five cases, that is, when human beings are 1) navigating in information systems with desktop computers, 2) navigating in three-dimensional virtual environments, 3) navigating in information systems with mobile computers, 4) navigating with wearable computers, and 5) navigating with embedded technology. However, the wayfinding task in a real environment or context can focus only on mobile, wearable or embedded technology. Furthermore, these navigation studies with mobile, wearable and embedded technology can take place indoors or outdoors. The main difference between navigation with desktop and mobile, wearable and embedded computers is that the latter is designed to be carried out by pedestrians or vehicle drivers. In these cases, the navigation may not be the primary task of the users to the same extent that it could be when users are navigating with the desktop computers at their offices. In the first and second categories (see Table 2), there are similarities in research, for example, exploring orientation issues see (Tory et al., 2004). Moreover, in the last four categories there can also be similarities found in research, particularly if the focus is on wayfinding tasks. Wayfinding tasks are one of the key issues both when choosing the viewpoint in the research of three-dimensional virtual environments, and when providing instructions for finding the correct route for pedestrians or vehicle drivers.

In the research field of human computer-interaction, keyword classification systems reflect navigation research, which is currently more related to navigation in information systems. One of the most cited classifications is the ACM Computing Classification System (1998). According to this classification, navigation is part of the class H.5.4 Hypertext/Hypermedia, Navigation. However, if we analyze the empirical data of this review, the researchers themselves have taken a much broader view, describing their navigation research using the primary keywords of the ACM Classification system. They describe their research mainly using the ACM Classification
TABLE II.

SUMMARY OF ARTICLES CATEGORISED BY TECHNOLOGY

\begin{tabular}{|l|c|}
\hline & \multicolumn{1}{|c|}{$\begin{array}{c}\text { Total share of } \\
\text { reviewed articles }\end{array}$} \\
\hline $\begin{array}{l}\text { Navigation in information systems } \\
\text { with desktop computers }\end{array}$ & $53 \%$ \\
\hline $\begin{array}{l}\text { Navigation in 3D virtual environ- } \\
\text { ments with desktop computers and } \\
\text { other devices }\end{array}$ & $11 \%$ \\
\hline $\begin{array}{l}\text { Navigation in information systems } \\
\text { with mobile devices }\end{array}$ & $31 \%$ \\
\hline $\begin{array}{l}\text { Navigation in information systems } \\
\text { with wearable devices }\end{array}$ & $2 \%$ \\
\hline $\begin{array}{l}\text { Navigation in information systems } \\
\text { with embedded technology }\end{array}$ & $5 \%$ \\
\hline
\end{tabular}

system with primary keyword (53 \% of the total papers) into the class H.5.2 User Interfaces. In addition, classes such as K Computing Milieux, C.3 Special-Purpose and application-based systems, Real-time and embedded systems, J. Computer Applications, and D Software, are used to describe the navigation research. Analyzing the five different research focuses (see Table 2) in general terms by ACM, it seems that navigation research with desktop computers covers all the areas, whereas the non-desktop navigation research still primarily focuses on issues of design and human factors, and less on experimentation and theory development. This is the case particularly with navigation research of wearable and embedded technology. It seems that research related to design, human factors, and performance is covered in all three technologybased navigation research domains. Even if studies are categorized with the technology-driven classification presented in the Table 2, more detailed analysis with key concepts, navigation research methods, and outcomes of the studies is needed. With better understanding of the concepts, methods used and the results of previous navigation research, more detailed explanation of prior research within the research stream is found and therefore arguments for future research trends and directions can be based on more solid ground.

\section{A. Navigation in information systems with desktop computers}

According to our data, current navigation research in the field of human computer interaction primarily concentrates on examining how users navigate within large information systems. This trend is easy to recognize by the amount of articles reviewed for this study, particularly from the CHI conference and the two HCI journals, TOCHI and Human Computer Studies. The total share of the articles reviewed in this study is 53\%. This figure does not include navigation research into three-dimensional virtual environments. The main focus of navigation research (see Table 4) covers a wide range of issues from user-related issues to social navigation and multimodal interaction. It is clear that this type of navigation research has the longer research tradition compared with nondesktop navigation research, and therefore desktop navigation research covers a wider range of research topics. The key topics of user-related issues of research includes, for example, gender and age issues in addition to user adaptability, whereas the rest of research focuses on the impact of navigating with other users (social navigation), user interface design, navigation techniques (panning, 
scrolling etc.), searching and browsing, filtering and recommending, and multimodal interaction. However, research into developing usability evaluation methods is also the current centre of attention of this type of navigation research.

The primary research methods for navigation research on desktop navigation are quantitative and experimental research methods. The data-gathering methods and dataanalyzing methods are most often based on statistical analysis. Only a few, (see Wall and Brewster, 2006), if any, research investigations were conducted using qualitative methods. Main findings covers a wide range of navigation techniques, theoretical developments, design guidelines for user interfaces, usability evaluation methods, new systems for recommend users, and issues related to social navigation.

As a summary, navigation HCI research with desktop computers during the 2000s seems to explore how to develop techniques to navigate, how to present and search/browse information, what kind of differences there are between women and men navigators and users with different ages, in addition to the impact of other navigators. Moreover, how to evaluate usability of navigation is also an important research topic. As a result, system development, design guidelines and method in addition to theoretical development can be presented.

\section{B. Navigation in three-dimensional virtual environments}

A total of $11 \%$ of the articles reviewed concerned navigation research in three-dimensional virtual environments. The key focus of the research (see Table 5) is covering user-related issues, social navigation and viewpoint and orientation issues. However, evaluation methods, multimodal interaction and user interface issues are lacking this type of research based on the reviewed articles. The main research methods are quantitative, experimental methods, for example, task-based controlled laboratory tests.

The main findings of this type of navigation research includes, for example, the development of new navigation techniques, e.g., (Tan et al, 2001), choosing orientation (Tory et al., 2004), or viewpoint Tatemura (2000). Furthermore, user interface-related studies resulted in an intelligent navigation interface with a personalisable assisting mechanism ( $\mathrm{Li}$ and Hsu, 2004), and more explicit or exaggerated representations of actions (Hindmarsh et al., 2000).

To summarize, navigation research of threedimensional virtual environments during the 2000s covered how users orientate and choose a viewpoint, what kind of navigation techniques users have, how to present the information of an avatar, the impact of other navigators and the gender of a user. The navigation research related to virtual environments is resulting techniques of navigation, choosing viewpoint and orientation and mechanisms of representations.

\section{Navigation in information systems with mobile technology}

In relation to research on navigation in information systems with non-desktop computers, and particularly with mobile (or handheld devices), the total share is $31 \%$ of the all reviewed articles.
TABLE III.

KEY CONCEPTS OF NAVIGATION IN INFORMATION SYSTEMS WITH DESKTOP COMPUTERS

\begin{tabular}{|c|c|}
\hline Research focus & Concepts \\
\hline $\begin{array}{l}\text { Navigation tech- } \\
\text { niques }\end{array}$ & $\begin{array}{l}\text { panning, hop, scrolling, fisheye, click action, } \\
\text { crossover effect, dynamic/ static peephole }\end{array}$ \\
\hline $\begin{array}{l}\text { Searching } \\
\text { browsing }\end{array}$ & $\begin{array}{l}\text { faceted search, visual data browsing, interacting } \\
\text { with search-engines }\end{array}$ \\
\hline Social navigation & $\begin{array}{l}\text { social affordance, socially translucent systems, } \\
\text { social search, social markers }\end{array}$ \\
\hline User-related issues & $\begin{array}{l}\text { gender and age issues, user adaptability, web } \\
\text { pages visited }\end{array}$ \\
\hline $\begin{array}{l}\text { Multimodal inter- } \\
\text { action }\end{array}$ & $\begin{array}{l}\text { tactile interaction, speech recognition, multi- } \\
\text { point interaction }\end{array}$ \\
\hline $\begin{array}{l}\text { Usability evalua- } \\
\text { tion }\end{array}$ & $\begin{array}{l}\text { evaluation of } 3 \mathrm{D} \text { techniques, cognitive walk- } \\
\text { through, easy prototyping, interpretability, auto- } \\
\text { matic checking tools }\end{array}$ \\
\hline $\begin{array}{l}\text { Information visu- } \\
\text { alization }\end{array}$ & scalability of information visualisation \\
\hline $\begin{array}{l}\text { Filtering and rec- } \\
\text { ommending }\end{array}$ & $\begin{array}{l}\text { content-based and collaborative filtering, per- } \\
\text { sonalization in e-commerce, resource adaptabil- } \\
\text { ity, }\end{array}$ \\
\hline interface & $\begin{array}{l}\text { overview display, levels of detail, off-screen } \\
\text { target selection, halo interface, reconnaissance } \\
\text { agents, zoomable user interfaces with and with- } \\
\text { out an overview }\end{array}$ \\
\hline Other issues & $\begin{array}{l}\text { task-based taxonomy, goal-directed behaviours, } \\
\text { Hyperbolic Tree, user's success rates, page re- } \\
\text { visitation, entry points in to video, effects of } \\
\text { context information (structural and temporal), } \\
\text { contextualising navigation, automatically build } \\
\text { associations in different media }\end{array}$ \\
\hline
\end{tabular}

TABLE IV.

KEY CONCEPTS OF NAVIGATION IN 3D VIRTUAL ENVIRONMENTS

\begin{tabular}{|l|l|}
\hline Research focus & \multicolumn{1}{|c|}{ Concepts } \\
\hline $\begin{array}{l}\text { Navigation tech- } \\
\text { niques }\end{array}$ & $\begin{array}{l}\text { a personalisable assisting mechanism, tracking } \\
\text { system, Speed-coupled Flying with Orbiting }\end{array}$ \\
\hline Orientation & $\begin{array}{l}\text { performance differences for 3D orientation, spatial } \\
\text { orientation tasks }\end{array}$ \\
\hline Viewpoint & $\begin{array}{l}\text { Semi-distorted views to support peripheral aware- } \\
\text { ness; transition between local and global view, } \\
\text { views blocked by obstacles }\end{array}$ \\
\hline Social navigation & sensitive to the actions of others \\
\hline Navigation task & spatial orientation task \\
\hline $\begin{array}{l}\text { User related } \\
\text { issues }\end{array}$ & gender bias, gender-specific navigation, \\
\hline $\begin{array}{l}\text { Information } \\
\text { vizualisation }\end{array}$ & $\begin{array}{l}\text { explicit or exaggerated representations of actions } \\
\text { provided by avatars }\end{array}$ \\
\hline
\end{tabular}

It is argued here that the main differences in navigation research between research on navigation in information systems and navigation with mobile devices in real environments is the impact of context. Tamminen et al.(2004) have stated that in mobile contexts, users' internal factors are different and external factors are dynamic and unpredictable. Furthermore, they argue that in relation to a mobile context, users solve navigation problems with social solutions, both national and within the mobile context, and there are temporal tensions, such as acceleration, declaration, hurrying, normal and waiting. Regarding the user interface issues, modality selection and interruption management are two of the main issues (Tamminen et al., 2004) in mobile navigation. According to the data of this study, the research focus of navigation research with mo- 
bile devices is on searching and exploring, multimodal interaction, user-related issues, user interface and navigation techniques (see Table 6). The key issues in userrelated themes are limited to the impact of age and the urban environment.

Main findings of non-desktop navigation research are related to interaction design, for example, Holland et al., (2002) and adaptability, e.g., Baus et al., (2002).

To summarize, navigation research with mobile technology during the 2000s explores navigation techniques, how to search and explore information, the possible impact of age and spatially-aware displays on navigation, in addition to how to design user interfaces and tailor the presentation information. In multimodal interaction, speech seems to be emphasized as the most popular modality.

\section{Navigation in information systems with wearable and with embedded technology}

In the research field of HCI, navigation with wearable computers is not yet in the mainstream of the current research. Of the reviewed articles, the total share was less than $2 \%$ of all the articles. The main focus of the research concentrates on interaction and user interface topics. The key concepts of research (see Table 7) involves primarily how simple interaction with wearable computers can be conducted. Other research interests include studies on positioning and measuring.

The main findings include issues such as presenting a platform or a prototype for wearable computing, or a map application, see for example, Raghunath and Narayanaswami (2002), Rantanen et al., (2002). Navigation HCI research during the 2000s is at an early phase. The amount of published articles are as yet very few and the topics concentrated on issues such as basic interaction and the design of user interfaces in this type of navigation research.

The embedded technology in this study is defined as including large displays, outdoors or indoors, ubiquitous and pervasive systems. The total share of this type of navigation research in this study is $5 \%$. The main focus of this type of research seems to focus on navigation techniques and displays (see Table 8). In other words, issues such as the adaptability of displays and tangible displays, besides the design of sizes and visual angles of displays, are highlighted in the navigation research.

The main findings relate to the design issues of the displays, such as size [24], adaptability and choosing the visual angle, or comparing physical and virtual navigation, for example, (Ball et al., 2007).

\section{E. Special case: Navigation in a real physical environment with mobile/ wearable/embedded technology}

Of the reviewed articles in this study, navigation with mobile devices includes special cases, for example, where the users' actions involves navigation tasks in a real environment with a mobile system particularly designed for support navigation and wayfinding in a real environment. It is argued here that in most cases of this type of navigation, the role of navigation in the information system is the secondary task, whereas the primary task is the navigation (by walking, driving a car, or a bike) in a real physical
TABLE V.

KEY CONCEPTS OF NAVIGATION IN INFORMATION SYSTEMS WITH MOBILE COMPUTERS

\begin{tabular}{|l|l|}
\hline Research focus & \multicolumn{1}{|c|}{ Concepts } \\
\hline $\begin{array}{l}\text { Navigation } \\
\text { techniques }\end{array}$ & static and dynamic peephole navigation \\
\hline $\begin{array}{l}\text { Searching and } \\
\text { exploring }\end{array}$ & $\begin{array}{l}\text { navigating web pages, effective browsing, tailor- } \\
\text { ing information }\end{array}$ \\
\hline $\begin{array}{l}\text { Multimodal } \\
\text { interaction }\end{array}$ & voice response \\
\hline $\begin{array}{l}\text { User-related } \\
\text { issues }\end{array}$ & age, urban people \\
\hline User interface & $\begin{array}{l}\text { inconsistent UIs, speech-based UI, an expressive } \\
\text { representation for location }\end{array}$ \\
\hline Context & spatially aware displays \\
\hline Other & $\begin{array}{l}\text { improving productivity and efficiency, personal- } \\
\text { ised service, hybrid system, decision-theoretic } \\
\text { handheld system }\end{array}$ \\
\hline
\end{tabular}

TABLE VI.

KEY CONCEPTS OF NAVIGATION IN INFORMATION SYSTEMS WITH WEARABLE COMPUTERS

\begin{tabular}{|l|l|}
\hline \multicolumn{1}{|c|}{$\begin{array}{c}\text { Research } \\
\text { focus }\end{array}$} & \multicolumn{1}{c|}{ Concepts } \\
\hline Interaction & Automatic emergency message \\
\hline User interface & $\begin{array}{l}\text { Navigation aids, a map application, a visualisation } \\
\text { method }\end{array}$ \\
\hline Other & $\begin{array}{l}\text { Communication, positioning. measuring the human } \\
\text { and the environment, a wearable computing platform } \\
\text { on a wrist }\end{array}$ \\
\hline
\end{tabular}

TABLE VII.

KEY CONCEPTS OF THE ARTICLES CONCERNING NAVIGATION IN INFORMATION SYSTEMS WITH EMBEDDED COMPUTERS

\begin{tabular}{|l|l|}
\hline \multicolumn{1}{|c|}{ Research focus } & \multicolumn{1}{|c|}{ Concepts } \\
\hline Design factors & display size, visual angle constant \\
\hline $\begin{array}{l}\text { Multimodal inter- } \\
\text { action }\end{array}$ & tangible displays \\
\hline User interface & adaptive displays \\
\hline $\begin{array}{l}\text { Navigation tech- } \\
\text { nique }\end{array}$ & $\begin{array}{l}\text { Physical vs. virtual navigation, spatial orienta- } \\
\text { tion, directional signs }\end{array}$ \\
\hline Other & user performance \\
\hline
\end{tabular}

environment. This is not the case when users are navigating, for example, with desktop computers in virtual environments. The possible misunderstanding and uncertainty with navigation concepts between these research fields may be apparent. Therefore, it is suggested here that we should clarify whether the research is about virtual navigation (in an information system with desktop/mobile/embedded technology) or (real) navigation (in a real environment with technology). In most cases, this may be obvious, but above all, when the research into virtual navigation is seeking and developing novel methods and concepts based on the principles of real navigation, for example, when using landmarks and utilizing navigation strategies, the potential for misinterpretation is real.

When exploring navigation HCI research that focuses on supporting navigation tasks with mobile technology, Table 9 describes how that navigation research focuses on issues of context (indoor, outdoor, in-vehicle, pedestrian). The user-related key concepts seem to focus on the impact of visual ability and the impact of indoor or outdoor navigation, as well as whether the navigators are acting as a driver or a pedestrian. 
TABLE VIII.

KEY CONCEPTS OF THE ARTICLES

\begin{tabular}{|l|l|}
\hline Research focus & \multicolumn{1}{|c|}{ Concepts } \\
\hline Wayfinding & $\begin{array}{l}\text { Wayfinding strategies, route guidance, situated } \\
\text { navigation, navigation task }\end{array}$ \\
\hline Indoor & Hybrid system \\
\hline Outdoor & Wayfinding, context awareness \\
\hline $\begin{array}{l}\text { Pedestrian } \\
\text { navigation }\end{array}$ & $\begin{array}{l}\text { Navigation assistance, perceptible landmarks, uncer- } \\
\text { tain predictions }\end{array}$ \\
\hline User interface & $\begin{array}{l}\text { Wearable adjustable 3D version of the map applica- } \\
\text { tion, the maintenance of forward/ up correspon- } \\
\text { dence, spatially aware display, adaptive route direc- } \\
\text { tions }\end{array}$ \\
\hline $\begin{array}{l}\text { In-vehicle } \\
\text { navigation }\end{array}$ & $\begin{array}{l}\text { Driving performance and listening synthetic and } \\
\text { natural speech, speech-based UI, mismatch between } \\
\text { the complexity of maps and the attention demands } \\
\text { of driving }\end{array}$ \\
\hline $\begin{array}{l}\text { Embedded } \\
\text { technology }\end{array}$ & $\begin{array}{l}\text { Scalability of information visualisation, target ac- } \\
\text { quisition, tangible user interface that facilitates } \\
\text { retrieval of historical stories in a tourist spot. Orien- } \\
\text { tation, movement, relative positions of physical, } \\
\text { mental rotation tasks }\end{array}$ \\
\hline $\begin{array}{l}\text { User-related } \\
\text { issues }\end{array}$ & $\begin{array}{l}\text { Visually-impaired people } \\
\text { Interaction }\end{array}$ \\
\hline Other & One-handed thumb \\
\hline
\end{tabular}

To summarize, navigation HCI research to support real navigation tasks is for the most part divided into indoor or outdoor navigation and/or into pedestrian navigation and in-vehicle navigation.

\section{CONCLUSIONS}

The main results of navigation research between 2000 and 2007 tend to contribute mainly by providing novel systems, guidelines ,e.g., Tan et al. (2006), for designers' user interface design, e.g., Raghunath and Narayanaswami (2002), McGrenere et al. (2007), systems or prototypes of systems, e.g. Holland et al. (2002), Cheverst et al. (2002), Yee (2003), Rantanen et al. (2002), and novel evaluation methods e.g., Takagi et al., (2007). It is quite interesting how research on navigation, whether it is focusing on navigation within an information system, or wayfinding in a real physical environment, possesses some similarities. On a general level, such research focuses on navigation strategies, and navigation techniques connect different kinds of navigation research (see Table 10). However, there are clear differences as well. For example, research on social issues in mobile navigation is lacking. Most of the research presents a cross-sectional view about the navigation issues. There are not so many studies focusing on the theory development of navigation or longitudinal studies indicating the impact of using navigation systems in a real or virtual environment. Fewer studies are about the possible transformation of user actions when they are navigating or using navigation systems.

One of the almost totally missing research topics of navigation HCI concerns navigation with multi-device environments. Nevertheless, most users are already using multiple devices in their everyday life. This review covers the field of navigation research during the 2000s so far. Based on the analyzed data, there are plenty of challenges for researchers and several directions for their future work. A general proposal for future work includes sugges-
TABLE IX

TAXONOMY FOR THE RESEARCH FOCUS

\begin{tabular}{|l|l|}
\hline & \multicolumn{1}{|c|}{ Research focus } \\
\hline $\begin{array}{l}\text { Navigation in information sys- } \\
\text { tems with desktop computers }\end{array}$ & $\begin{array}{l}\text { Evaluation methods, navigation } \\
\text { techniques, multimodal interaction, } \\
\text { social navigation }\end{array}$ \\
\hline $\begin{array}{l}\text { Navigation in 3D virtual envi- } \\
\text { ronments with desktop com- } \\
\text { puters and other devices }\end{array}$ & $\begin{array}{l}\text { Social navigation, performance } \\
\text { differences, orientation, viewpoint }\end{array}$ \\
\hline $\begin{array}{l}\text { Navigation in information sys- } \\
\text { tems with mobile devices }\end{array}$ & $\begin{array}{l}\text { Searching, exploring, user interface, } \\
\text { pedestrian navigation, in-vehicle } \\
\text { navigation }\end{array}$ \\
\hline $\begin{array}{l}\text { Navigation in information sys- } \\
\text { tems with wearable devices }\end{array}$ & $\begin{array}{l}\text { Navigation aids, communication, } \\
\text { user interface }\end{array}$ \\
\hline $\begin{array}{l}\text { Navigation in information sys- } \\
\text { tems with embedded technol- } \\
\text { ogy }\end{array}$ & $\begin{array}{l}\text { Display size, adaptive displays, user } \\
\text { performance }\end{array}$ \\
\hline
\end{tabular}

tions for conducting more qualitative research alongside quantitative research. For example, exploring the context and its impact on navigation with qualitative research methods, whether with desktop or mobile computers, may reveal critical factors about navigation. Furthermore, due to the fact that we are living and navigating in multidevice environments, much more research should be carried out on exploring what kinds of possible impact changing devices during a navigation task can cause. In additions, longitudial studies of navigation are needed to better understand how navigation is possible when changing the technology that users are provided with.

For non-desktop navigation research, there are gaps to fill if we compare navigation research into desktop navigation. First, it is strongly emphasized here that describing who the users are and how the sample of users for the tests and evaluations were chosen could be mentioned more precisely. People do have different kind of navigation strategies or techniques, see for example Czrewinski et al., (2002) and Guiard et al. (2007), and therefore it is more than crucial that these user-related issues should be explored. Navigation in a variety of contexts (indoor, outdoor, pedestrian, in-vehicle) has been explored, but it does not describe for example what kind of impact gender or age has on mobile navigation. Therefore, possibilities how to adapt novel navigation systems according to user's profile should be explored. Second, what is missing almost totally from non-desktop navigation research, is research on evaluation methods. For non-desktop navigation research, as distinct from the desktop environment, the fact that navigation cannot be the primary task of a user as often it is in a desktop navigation, should be noted in the research as well. In other words, what are the main challenges when people are navigating in real environments? Furthermore, what kind of challenges people face if navigation guidance is not presented on the screen of mobile device but it is, for example, projected on different surfaces.

Finally, based on this review, due to the possible misunderstanding and uncertainty with navigation concepts between the research fields of navigation in information systems and navigation with information systems, it is suggested here that we should clarify whether the research is about virtual navigation or navigation in a real environment. 


\section{REFERENCES}

[1] Amant, R., St. Christian, D. B. (2003). Environment modification in a simulated human-robot interaction task: experimentation and analysis. IUI'03 Proc. of the 8th international conference on intelligent user interfaces.

[2] Ball, R., North, C., and Bowman, D. A. (2007). Move to improve: promoting physical navigation to increase user performance with large displays. CHI '07 Proc of the SIGCHI Conference on Human Factors in Computing Systems. CHI '07. ACM, New York, NY, 191-200.

[3] Baus J., Krüger, A., Wahlster, W. (2002). A resource-adaptive mobile navigation system. IUI '02: Proc of the 7th international conference on intelligent user interfaces.

[4] Baus, J., Wasinger R., Aslan I., Krüger, A., Maier, A., Schwartz, T. (2007). Auditory perceptible landmarks in mobile navigation. IUI'07 Proc of the 12th international conference on Intelligent user interfaces.

[5] Cheverst, K., Davies, N., Mitchell, K., Friday, A., and Efstratiou, C. (2000). Developing a context-aware electronic tourist guide: some issues and experiences. CHI '00 Proc of the SIGCHI Conference on Human Factors in Computing Systems. CHI '00. ACM, New York, NY, 17-24.

[6] Cliburn, D., Winlock, T., Rilea, S., Van Donsel, M. (2007). Dynamic landmark placement as a navigation aid in virtual worlds. VRST '07: Proc of the 2007 ACM symposium on virtual reality software and technology.

[7] Czerwinski, M., Tan, D. S., and Robertson, G. G. (2002). Women take a wider view. $\mathrm{CHI}$ '02 Proc of the SIGCHI Conference on Human Factors in Computing Systems: Changing Our World, Changing Ourselves. ACM, New York, NY, 195-202

[8] Darken, R., Sibert, J. (1996). Navigating large virtual spaces. Int Journal of Human-Computer Interaction, January-March 1996, 8 (1), 49-72. doi:10.1080/10447319609526140

[9] Guiard, Y., Du, Y., and Chapuis, O. (2007). Quantifying degree of goal directedness in document navigation: application to the evaluation of the perspective-drag technique. CHI '07 Proc of the SIGCHI Conference on Human Factors in Computing Systems. ACM, New York, NY, 327-336.

[10] Hindmarsh, J., Fraser, M., Heath, C., Benford, S., and Greenhalgh, C. (2000). Object-focused interaction in collaborative virtual environments. ACM Transactions in Computing-Human Interaction, 7 (4), 477-509. doi:10.1145/365058.365088

[11] Holland, S., Morse, D. R., Gedenryd, H. (2002). AudioGPS: Spatial Audio Navigation with a Minimal Attention Interface, Personal and Ubiquitous Computing, 6 (4). doi: $10.1007 / \mathrm{s} 007790200025$

[12] Jöst, M., Häußler, J., Merdes M.,, Malaka R. (2005), Multimodal interaction for pedestrians: an evaluation study. IUI '05: Proc of the 10th international conference on intelligent user interfaces.

[13] Kjeldskov, J. \& Graham, C. (2003). A Review of MobileHCI Research Methods. In Lecture Notes in Computer Science: $\mathrm{Hu}$ man-Computer Interaction with Mobile Devices. 5th International Symposium, Mobile HCI 2003, pp.317-335. Berlin, Heidelberg: Springer-Verlag.

[14] Li.,T-Y, Hsu, S-W., (2004). An intelligent 3D user interface adapting to user control behaviors. IUI '04: Proc of the 9th international conference on intelligent user interfaces.

[15] Lynch, K. (1960). Image of the City. Cambridge: The Technology Press \& Harvard University Press.

[16] Mehra, S., Werkhoven, P., and Worring, M. (2006). Navigating on handheld displays: Dynamic versus static peephole navigation. ACM Transactions in Computing-Human Interaction 13 (4) , 448457.

[17] McGrenere, J., Baecker, R. and Booth, K., S. (2007): A field evaluation of an adaptable two-interface design for feature-rich software. In ACM Transactions on Computer-Human Interaction, $14(1), 3$

[18] Patton, M., Q. (2002). Qualitative Evaluation and Research Methods. Thousands Paks. CA: Sage Publication.

[19] Raghunath, M. T., Narayanaswami, C., (2002), User Interfaces for Applications on a Wrist Watch. Personal and Ubiquitous Computing, 6 (1). doi:10.1007/s007790200002

[20] Rantanen, J., Impiö, J., Karinsalo, T., Malmivaara, M., Reho, A., Tasanen, M., and Vanhala, J. (2002). Smart Clothing Prototype for the Arctic Environment, Personal and Ubiquitous Computing, 6 (1). doi:10.1007/s007790200001

[21] Swanson E.B. and N.C. Ramiller, (1993). Information systems research thematics: Submissions to a new journal, 1987-92. Information Systems Research 4, (4) 299-330. doi:10.1287/isre.4.4.299

[22] Takagi, H., Saito, S., Fukuda, K., and Asakawa, C. (2007). Analysis of navigability of Web applications for improving blind usability. ACM Transactions on Computer-Human Interaction 14 (3) 13. doi:10.1145/1279700.1279703

[23] Tamminen, S., Oulasvirta, A., Toiskallio, K., Kankainen, A. (2004). Understanding mobile contexts, May 2004 Personal and Ubiquitous Computing, 8 (2). doi:10.1007/s00779-004-0263-1

[24] Tan, D. S., Robertson, G. G., and Czerwinski, M. (2001). Exploring 3D navigation: combining speed-coupled flying with orbiting. CHI '01 Proc of the SIGCHI Conference on Human Factors in Computing Systems.. ACM, New York, NY, 418-425.

[25] Tan, D. S., Gergle D., Scupelli P., Pausch, R., (2006). Physically large displays improve performance on spatial tasks. ACM Transactions on Computer-Human Interaction, 13 (1). doi:10.1145/1143518.1143521

[26] Tatemura, J., (2000), Virtual reviewers for collaborative exploration of movie reviews. IUI '00: Proc of the 5th international conference on Intelligent user interfaces

[27] Tolman, E. (1948). Cognitive maps in rats and men. Psychological Review, 55, 189-208. doi:10.1037/h0061626

[28] Tory, M., Moller, T., Atkins, S., Kirkpatrick, A., E., (2004). Combining 2D and $3 \mathrm{D}$ views for orientation and relative position tasks. CHI '04: Proc of the SIGCHI conference on Human Factors in Computing Systems.

[29] Vinson, N., G., (1999). Design guidelines for landmarks to support navigation in virtual environments. CHI '99: Proc of the SIGCHI conference on Human Factors in Computing Systems: the CHI is the limit.

[30] Wall, S. and Brewster, S. (2006). Feeling what you hear: tactile feedback for navigation of audio graphs. CHI '06 Proc of the SIGCHI Conference on Human Factors in Computing Systems. R. Grinter, T. Rodden, P. Aoki, E. Cutrell, R. Jeffries, and G. Olson, Eds. CHI '06. ACM, New York, NY, 1123-1132.

[31] Yee, K. (2003). Peephole displays: pen interaction on spatially aware handheld computers. CHI '03 Proc of the SIGCHI Conference on Human Factors in Computing Systems. CHI '03. ACM, New York, NY, 1-8.

\section{ACKNOWLEDGMENT}

The author would like to acknowledge the partners of TOPI project at the Tampere University of Technology and at the University of Tampere

\section{AUTHOR}

Teija Vainio. Author is a researcher at the Human Centered Technology Unit, Tampere University of Technology in Finland (e-mail: teija.vainio@tut.fi).

Submitted, March, 16, 2010. Published as resubmitted by the author on june $29^{\text {th }}, 2010$. 